\title{
ISOMORPHISMS IN EQ-ALGEBRAS
}

\author{
M. BAKHSHI, M.R. KHAVARI \\ AND \\ M. NAZIFI \\ University of Bojnord \\ Department of Mathematics, Bojnord, Iran \\ e-mail: bakhshi@ub.ac.ir \\ khavari66@gmail.com \\ mohadesenazifi1866@gmail.com
}

\begin{abstract}
In this paper we investigate some isomorphism theorems in EQ-algebras. After establishing some basic results we give the Fundamental Homomorphism Theorem and by using it we state and prove some other isomorphism theorems. We also state and prove a correspondence theorem. Next, using some results of the theory of universal algebra we characterize subdirectly irreducible EQ-algebras.
\end{abstract}

Keywords: many-valued logics, Fuzzy type theory, EQ-algebra, homomorphism theorems.

2010 Mathematics Subject Classification: 03B15, 08A72.

\section{REFERENCES}

[1] P.B. Andrews, An Introduction to Mathematical Logic and Type Theory: To Truth Through Proof (Kluwer Academic Publishers, Dordrecht, 2002). doi:10.1007/978-94-015-9934-4

[2] R.A. Borzooei and B.G. Saffar, States on EQ-algebras, J. Intell. Fuzzy Systems 29 (2015) 209-221. doi:10.3233/IFS-151588

[3] S. Burris and H.P. Sankapannavar, A course in universal algebra, Graduate Text Math. 78 (1981).

[4] N. Mohtashamnia and L. Torkzadeh, The lattice of prefilters of an EQ-algebra, Fuzzy Sets and Syst. 311 (2017) 86-98. doi:10.1016/j.fss.2016.04.015 
[5] V. Novák, On fuzzy type theory, Fuzzy Sets and Syst. 149 (2005) 235-273. doi:10.1016/j.fss.2004.03.027

[6] V. Novák and B. De Baets, EQ-algebras, Fuzzy Sets and Syst. 160 (2009) 29562978.

doi:10.1016/j.fss.2009.04.010

[7] V. Novák, M. El-Zekey and Radko Mesiar, On good EQ-algebras, Fuzzy Sets and Syst. $178(2011) 1-23$.

doi:10.1016/j.fss.2011.05.011

[8] M. Ward and R.P. Dilworth, Residuated lattices, Trans. Amer. Math. Soc. 45 (1939) $335-354$.

doi:10.1090/S0002-9947-1939-1501995-3

Received 6 November 2019

Revised 23 March 2020

Accepted 6 July 2020 